\title{
Evaluation of the association of bruxism, psychosocial and sociodemographic factors in preschoolers
}

\section{Monalisa Cesarino GOMES(a) Érick Tássio NEVES(a) \\ Matheus França PERAZZO(b) \\ Emilly Gabrielle Carlos de SOUZA ${ }^{(a)}$ \\ Júnia Maria SERRA-NEGRA(b) \\ Saul Martins PAIVA ${ }^{(b)}$ \\ Ana Flávia GRANVILLE-GARCIA(a)}

(a) Universidade Estadual da Paraíba - UEPB, Dental School, Department of Dentistry, Campina Grande, PB, Brazil.

(b) Universidade Federal de Minas Gerais UFMG, Dental School, Department of Pediatric Dentistry and Orthodontics, Belo Horizonte, MG, Brazil.
Declaration of Interest: The authors certify that they have no commercial or associative interest that represents a conflict of interest in connection with the manuscript.

\section{Corresponding Author:}

Ana Flávia Granville-Garcia

E-mail: anaflaviagg@hotmail.com

htips://doi.org/10.1590/1807-3107bor-2018.vol32.0009

Submitted: November 03, 2016

Accepted for publication: December 13, 2017

Last revision: January 11, 2018
Abstract: The aim of the present study was to evaluate factors associated with sleep bruxism in five-year-old preschool children. A preschool-based cross-sectional study was conducted with 761 pairs of children and their parents/caregivers. Sleep bruxism was diagnosed using a questionnaire administered to the parents/caregivers, who also answered questionnaires addressing sociodemographic data and parent's/caregiver's sense of coherence. Clinical oral evaluations of the children to determine dental caries, traumatic dental injuries, malocclusion and tooth wear were performed by two researchers who had undergone a training exercise (interexaminer Kappa: 0.70 to 0.91 ; intraexaminer Kappa: 0.81 to 1.00 ). Descriptive analysis and logistic regression for complex samples were carried out $(\alpha=5 \%)$. The prevalence of sleep bruxism among the preschool children was $26.9 \%$. The multivariate analysis revealed that bruxism was associated with poor sleep quality $(\mathrm{OR}=2.93$; $95 \mathrm{CI}$ : $1.52-5.65)$ and tooth wear $(\mathrm{OR}=2.34$; 95\%CI: 1.39-3.96). In the present study, sleep bruxism among preschool children was associated with tooth wear and poor sleep quality of the child. In contrast, psychosocial aspects (sense of coherence) were not associated with sleep bruxism.

Keywords: Sleep Bruxism; Child; Sense of Coherence.

\section{Introduction}

Sleep bruxism is a parafunction characterized by grinding one's teeth during sleep. ${ }^{1}$ The prevalence of this habit in children ranges from 14.0 to $36.8 \% .^{2,3,4,5}$ Imbalanced bruxism can exert a negative effect on the functioning of the stomatognathic system. ${ }^{6}$ The physiopathology of this disorder remains unknown, but several factors are related to the emergence of bruxism. The multifactor etiology involves factors influenced by the central nervous system and genetics, as well as psychosocial aspects. ${ }^{7}$

Different methods are used to diagnose sleep bruxism, including the use of optical reading, the analysis of models, polysomnography, the assessment of masseter muscle contraction through bite strip electrodes, and self-reports/parental reports. ${ }^{8,9}$ It is noteworthy that the American Academy of Sleep Medicine (AASM) considers the reports of parents/caregivers to be quite reliable $\mathrm{e}^{10}$ and sufficiently objective for use in epidemiological studies. 
Socioeconomic and cultural characteristics may be associated with the prevalence of sleep bruxism. ${ }^{7}$ A previous study found that this disorder was more prevalent among children from families with a better socioeconomic status. ${ }^{11}$ Although this association has not yet been clarified, it may be related to the number of daily activities children perform, an issue that needs to be studied further.

Psychosocial factors, such as a mother's sense of coherence, are related to oral health problems in children..$^{12}$ The sense of coherence involves the capacity to adapt to stress, and has been found to be associated with oral problems. ${ }^{12}$ Sleep bruxism in children is reported to be moderately associated with parafunctional behaviors and stress. ${ }^{8}$ Such psychosocial issues should be addressed, since individuals tend to release tension accumulated during the day through chronic sleep bruxism..$^{13}$

Thus, the aim of the present study was to evaluate sociodemographic, clinical and psychosocial factors associated with sleep bruxism, in a representative sample of preschool children.

\section{Methods}

\section{Sample characteristics and study design}

A representative, preschool-based, cross-sectional study was conducted with a sample of 761 pairs of parents/caregivers and five-year-old children enrolled in private and public preschools in the city of Campina Grande, Brazil. The participants were selected from a total population of 14,360 children in this age group.

A two-stage sampling strategy was employed to ensure representativeness. The distribution of five-year-old children from each administrative district of Campina Grande was determined according to information provided by the Municipal Secretary of Education. The sample was stratified according to district and type of preschool (public and private). In the first stage, preschools were randomly selected from each district, proportional to the number in each administrative district (five in District I, ten in District II, five in District III, 11 in District IV, ten in District V and seven in District VI). The second phase consisted of the selection of children using a simple randomization procedure. The ratio of the total population enrolled in private and public preschools in each administrative district was maintained in the sample distribution. The sample size was calculated based on a $5 \%$ margin of error, $95 \%$ confidence level and a correction factor of 1.6, to compensate for the effect of the design. Since the prevalence of bruxism was unknown, a prevalence rate of $50 \%$ was considered as the percentage estimated for increasing the power, and as a value that would provide the largest sample, regardless of the actual prevalence. ${ }^{14}$ Twenty of the 129 public preschools, and 28 of the 134 private preschools were randomly selected. The sample size was estimated at 615 preschool children, to which an additional $20 \%$ was added to compensate for possible dropouts, for a total of 769 preschool children.

\section{Eligibility criteria}

Five-year-old children with no systematic diseases (based on parents'/caregivers' reports), enrolled at public and private preschools, were included in the sample. Parents/caregivers needed to be fluent in Brazilian Portuguese and spend at least 12 hours a day with the child. The exclusion criteria were the presence of one or more erupted permanent teeth and a history of orthodontic treatment.

\section{Training and calibration exercise}

A specialist in pediatric dentistry coordinated the theoretical step, involving a discussion of the criteria for diagnosis of the oral conditions. In the clinical step, two dentists examined 40 previously selected children at a preschool chosen by convenience. This preschool was not part of the main study. Interexaminer agreement was tested by comparing each examiner with an experienced oral health professional. The interexaminer Kappa coefficient was calculated for dental caries $(K=0.80$ to 0.90$)$, traumatic dental injury (TDI) $(\mathrm{K}=0.88$ to 0.90$)$, malocclusion $(\mathrm{K}=0.86$ to 0.91$)$ and tooth wear ( $\mathrm{K}=0.70$ to 0.73 ). The intraexaminer Kappa coefficient was determined after a one-week interval: dental caries ( $\mathrm{K}=0.87$ to 1.00$)$, TDI ( $\mathrm{K}=0.82$ to 0.87 ), malocclusion ( $\mathrm{K}=0.94$ to 1.00 ) and tooth wear $(\mathrm{K}=0.81$ to 1.00$)$. Interexaminer and intraexaminer agreement was considered adequate. Values between 0.61 and 0.80 are considered good, and values between 0.81 and 1.00 are considered very good. ${ }^{15}$ 


\section{Pilot study}

A pilot study was conducted to test the methodology. The participants in the pilot study $(n=45)$ were not included in the main sample. Considering that there were no misunderstandings regarding the questionnaires or the methodology, no changes to the data collection process were deemed necessary.

\section{Non-clinical data collection}

Non-clinical data were collected using the short version of the Sense of Coherence Scale (SOC-13) to evaluate the parent's/caregiver's SOC ${ }^{16}$, in addition to questionnaires addressing sociodemographic data. Parents/caregivers were previously contacted and invited to attend a meeting at the preschools, during which they received clarifications regarding the objectives of the study.

The Brazilian version of the SOC-13 consists of 13 items, each with five response options. Three items can be considered representative of the SOC-13: a) "Are you interested in what occurs around you?" b) "Have you been disappointed by people whom you counted on?" and c) "Do you have confusing notions and feelings?"17. The final score ranges from 13 to 65 , with higher scores denoting a greater capacity of adaptation to stress. ${ }^{17}$ For statistical purposes, the SOC was dichotomized as strong or weak based on the median..$^{12}$ This questionnaire was administered to the parents/caregivers of the preschool children, to evaluate parent's/caregiver's sense of coherence.

The following sociodemographic characteristics were investigated: child's gender, type of preschool and monthly household income (categorized based on the median, which was equal to R \$1000/US\$280); parent's/caregiver's schooling and age. These variables were categorized based on previous studies. ${ }^{18,19}$ Data on the children's history (at some time in their life) were also collected through questions posed to parents/caregivers. The parents/caregivers also furnished data on their perception of the children's sleep quality (Does your child sleep well?) and the habit of nail biting.

\section{Clinical data collection}

Prior to the examination, the children's teeth were brushed to remove plaque and facilitate the diagnosis. Oral examinations were performed in the knee-to-knee position, with the aid of a portable lamp attached to the examiner's head (Petzl Zoom headlamp, Petzl America, Clearfield, UT, USA). The dentists used individual protective equipment, a sterilized mouth mirror (PRISMA ${ }^{\circledR}$, São Paulo, SP, Brazil), a sterilized Williams probe (WHO-621, Trinity ${ }^{\circledR}$, Campo Mourão, Paraná, Brazil) and gauze to dry the teeth. Examination of the oral conditions was performed based on established clinical criteria.

The diagnosis of sleep bruxism was based on the reports of tooth grinding during sleep, as proposed by the AASM for preschool children, ${ }^{10}$ and employed in a previous study. ${ }^{20}$ The AASM criteria include: parents who report an occurrence of audible tooth grinding at night, but no other medical or mental disorders (e.g., sleep-related epilepsy, accounts of abnormal movements during sleep), and no other sleep disorders (e.g., obstructive sleep apnea syndrome). Accordingly, children with any systemic alteration were excluded from the study, as mentioned above. As recommended, the following question was posed to parents/caregivers to determine possible sleep bruxism in the children, among the self-reports, questionnaires and/or patient history part of the clinical examination: ${ }^{21}$ "Does your child grit his/her teeth while he/she sleeps?" The children were also submitted to a clinical examination to determine tooth wear, and evaluate its possible association with sleep bruxism. This oral condition was diagnosed in the presence of wear on the incisal surfaces of the anterior teeth, and/or occlusal surfaces of the posterior teeth.

Dental caries was diagnosed using the International Caries Detection and Assessment System (ICDAS-II) ${ }^{22}$. TDI was diagnosed using the criteria established by Andreasen et al. ${ }^{23}$ Malocclusion was recorded in the presence of at least one of the following conditions: increased overbite $(>2 \mathrm{~mm})$, increased overjet $(>2 \mathrm{~mm})$, anterior open bite, anterior crossbite and posterior crossbite. $^{24,25}$ Following the clinical examinations, a fluoride varnish was applied to all the children's teeth as a preventive and therapeutic measure for dental caries. In addition, a letter was sent to all the parents informing them of the oral diagnosis of the preschool children, and explaining the need for dental care. 


\section{Statistical analysis}

Data organization and statistical analysis were performed using the Statistical Package for Social Sciences (SPSS for Windows, version 21.0, IBM Inc., Armonk, NY, USA). Frequency distribution of the data was determined to characterize the sample. Logistic regression for complex samples was performed to test associations between sleep bruxism in the preschool children and the independent variables. The backward stepwise procedure was used for the selection of variables with a $p$ value $<0.20$ in the bivariate analysis. Variables with a p-value $<0.05$ in the adjusted analyses were maintained in the final regression model.

\section{Ethical issues}

This study was conducted in accordance with the Declaration of Helsinki, and was reviewed independently and approved by the Human Research Ethics Committee of the State University of Paraiba, Brazil, under protocol number 38937714.0.0000.5187. The parents/caregivers received clarifications regarding the objectives of the study and signed a statement of informed consent.

\section{Results}

A total of 761 children and their respective parents/caregivers participated in the present study. The response rate was $98.9 \%$. Eight pairs were excluded due to incomplete questionnaires. The questionnaires were answered by mothers $(86.7 \%)$, fathers $(8.0 \%)$ and others (5.3\%). Table 1 displays the data used to characterize the sample.

Logistic regression for complex samples was performed to determine factors associated with sleep bruxism among the preschool children. In the bivariate analysis, the poor sleep quality of the child and tooth wear were associated with sleep bruxism $(p<0.05)$. In the multivariate analysis, the same variables remained in the final model: poor sleep quality of the child (OR $=2.93$; 95\%CI: $1.52-5.65)$ and tooth wear $(\mathrm{OR}=2.34 ; 95 \% \mathrm{CI}$ : 1.39-3.96) (Table 2).

\section{Discussion}

The present study was conducted to evaluate sociodemographic, clinical and psychosocial factors
Table 1. Characterization of the sample.

\begin{tabular}{|c|c|c|}
\hline \multirow{2}{*}{ Variable } & \multicolumn{2}{|c|}{ Frequency } \\
\hline & $\mathrm{N}$ & $\%$ \\
\hline \multicolumn{3}{|l|}{ Child's sex } \\
\hline Male & 399 & 52.4 \\
\hline Female & 362 & 47.6 \\
\hline \multicolumn{3}{|l|}{ Type of preschool } \\
\hline Private & 296 & 38.9 \\
\hline Public & 465 & 61.1 \\
\hline \multicolumn{3}{|c|}{ Monthly household income } \\
\hline$\leq$ US\$ 280 & 368 & 50.6 \\
\hline > US\$ 280 & 359 & 49.4 \\
\hline \multicolumn{3}{|l|}{ Mother's schooling } \\
\hline$\leq 8$ years of study & 226 & 29.8 \\
\hline$>8$ years of study & 532 & 70.2 \\
\hline \multicolumn{3}{|l|}{ Caregiver's age } \\
\hline$\leq 30$ years & 320 & 43.8 \\
\hline$>30$ years & 411 & 56.2 \\
\hline \multicolumn{3}{|l|}{ Child's sleep quality } \\
\hline Good & 705 & 92.8 \\
\hline Poor & 55 & 7.2 \\
\hline \multicolumn{3}{|l|}{ Nail biting habit } \\
\hline Yes & 237 & 31.6 \\
\hline No & 513 & 68.4 \\
\hline \multicolumn{3}{|l|}{ Restoration } \\
\hline Present & 121 & 15.9 \\
\hline Absent & 640 & 84.1 \\
\hline \multicolumn{3}{|l|}{ Tooth wear } \\
\hline Present & 593 & 77.9 \\
\hline Absent & 168 & 22.1 \\
\hline \multicolumn{3}{|l|}{ History of toothache } \\
\hline Yes & 179 & 23.8 \\
\hline No & 572 & 76.2 \\
\hline \multicolumn{3}{|l|}{ Dental caries } \\
\hline Absent & 67 & 8.8 \\
\hline Present & 694 & 91.2 \\
\hline \multicolumn{3}{|l|}{ Traumatic dental injury } \\
\hline Absent & 359 & 47.2 \\
\hline Present & 402 & 52.8 \\
\hline \multicolumn{3}{|l|}{ Malocclusion } \\
\hline Absent & 323 & 42.5 \\
\hline Present & 437 & 57.5 \\
\hline \multicolumn{3}{|c|}{ Parent's/caregiver's sense of coherence } \\
\hline Strong & 442 & 58.1 \\
\hline Weak & 319 & 41.9 \\
\hline \multicolumn{3}{|l|}{ Sleep bruxism } \\
\hline Present & 205 & 26.9 \\
\hline Absent & 556 & 73.1 \\
\hline
\end{tabular}


Table 2. Logistic regression for complex samples of sleep bruxism in preschool children and associated factors.

\begin{tabular}{|c|c|c|c|c|c|c|}
\hline \multirow{3}{*}{ Variable } & \multicolumn{2}{|c|}{ Bruxism } & \multirow{2}{*}{\multicolumn{2}{|c|}{$\begin{array}{c}\text { Bivariate } \\
\text { Unadjusted } O R^{* *}\end{array}$}} & \multirow{2}{*}{\multicolumn{2}{|c|}{$\begin{array}{c}\text { Multivariate } \\
\text { Adjusted OR† }\end{array}$}} \\
\hline & \multirow{2}{*}{$\begin{array}{c}\text { Present } \\
\mathrm{n}(\%)\end{array}$} & \multirow{2}{*}{$\begin{array}{c}\text { Absent } \\
\mathrm{n}(\%)\end{array}$} & & & & \\
\hline & & & $\mathrm{p}$-value & $(95 \% \mathrm{Cl})$ & $p$-value & $(95 \% \mathrm{Cl})$ \\
\hline \multicolumn{7}{|l|}{ Child's sex } \\
\hline Female & $93(25.7)$ & $269(74.3)$ & & 1.00 & - & - \\
\hline Male & $112(28.1)$ & 287(71.9) & 0.393 & $1.18(0.80-1.74)$ & - & - \\
\hline \multicolumn{7}{|l|}{ Mother's schooling } \\
\hline$\leq 8$ years of study & $45(19.9)$ & $181(80.1)$ & & 1.00 & - & - \\
\hline$>8$ years of study & $159(29.9)$ & $373(70.1)$ & 0.136 & $1.42(0.89-2.26)$ & - & - \\
\hline \multicolumn{7}{|c|}{ Monthly household income ${ }^{*}$} \\
\hline$\leq$ US\$ 280 & $92(25.0)$ & $276(75.0)$ & & 1.00 & - & - \\
\hline$>$ US\$ 280 & $102(28.4)$ & $257(71.6)$ & 0.588 & $1.11(0.75-1.66)$ & - & - \\
\hline \multicolumn{7}{|l|}{ Caregiver's age } \\
\hline$\leq 30$ years & $91(28.4)$ & $229(71.6)$ & 0.164 & $1.32(0.89-1.97)$ & - & - \\
\hline$>30$ years & $105(25.5)$ & $306(74.5)$ & & 1.00 & - & - \\
\hline \multicolumn{7}{|l|}{ Child's sleep quality } \\
\hline Good & $179(25.4)$ & $526(74.6)$ & & 1.00 & & 1.00 \\
\hline Poor & $26(47.3)$ & $29(52.7)$ & 0.003 & $2.63(1.38-4.99)$ & 0.001 & $2.93(1.52-5.65)$ \\
\hline \multicolumn{7}{|l|}{ Nail biting habit } \\
\hline Yes & $74(31.2)$ & $163(68.8)$ & 0.110 & $1.37(0.93-2.03)$ & - & - \\
\hline No & $128(25.0)$ & $385(75.0)$ & & 1.00 & - & - \\
\hline \multicolumn{7}{|l|}{ Restoration } \\
\hline Present & $30(24.8)$ & $91(75.2)$ & & 1.00 & - & - \\
\hline Absent & $175(27.3)$ & $465(72.7)$ & 0.317 & $1.29(0.78-2.13)$ & - & - \\
\hline \multicolumn{7}{|l|}{ Tooth wear } \\
\hline Present & $174(29.3)$ & $419(70.7)$ & 0.021 & $1.97(1.10-3.50)$ & 0.001 & $2.34(1.39-3.96)$ \\
\hline Absent & $31(18.5)$ & $137(81.5)$ & & 1.00 & & 1.00 \\
\hline \multicolumn{7}{|l|}{ History of toothache } \\
\hline Yes & $50(27.9)$ & $129(72.1)$ & 0.706 & $1.09(0.68-1.75)$ & - & - \\
\hline No & $155(27.1)$ & $417(72.9)$ & & 1.00 & - & - \\
\hline \multicolumn{7}{|l|}{ Dental caries } \\
\hline Absent & $17(25.4)$ & $50(74.6)$ & & 1.00 & - & - \\
\hline Present & $188(27.1)$ & $506(72.9)$ & 0.749 & $1.11(0.58-2.10)$ & - & - \\
\hline \multicolumn{7}{|l|}{ Traumatic dental injury } \\
\hline Absent & $90(25.1)$ & $269(74.9)$ & & 1.00 & - & - \\
\hline Present & $115(28.6)$ & $287(71.4)$ & 0.131 & $1.34(0.91-1.97)$ & - & - \\
\hline \multicolumn{7}{|l|}{ Malocclusion } \\
\hline Absent & $97(30.0)$ & $226(70.0)$ & 0.226 & $1.27(0.86-1.87)$ & - & - \\
\hline Present & $107(24.5)$ & $330(75.5)$ & & 1.00 & - & - \\
\hline \multicolumn{7}{|c|}{ Parent's/caregiver's sense of coherence } \\
\hline Strong & $111(25.1)$ & $331(74.9)$ & & 1.00 & - & - \\
\hline Weak & $94(29.5)$ & $225(70.5)$ & 0.274 & $1.24(0.84-1.83)$ & - & - \\
\hline
\end{tabular}

*Variables dichotomized by the median; ${ }^{* *}$ Logistic regression for complex samples of bruxism and independent variables. ${ }^{* * *}$ Variables incorporated into the multivariate model ( $p<0.20$ in unadjusted logistic regression): mother's schooling, caregiver's age, child's sleep quality, nail biting habit, tooth wear and traumatic dental injuries.

associated with sleep bruxism in preschool children. Tooth wear and poor sleep quality of the child were associated with the outcome, whereas no associations were found for the psychosocial or socioeconomic variables analyzed.
The prevalence of sleep bruxism was $29.1 \%$. Previous studies report prevalence rates of $14.0 \%$ to $36.8 \% ., 2,3,45$ This wide range may be attributed to the different diagnostic methods employed, thus underscoring the need to standardize the criteria for 
ultimately achieving greater advances in the study of sleep bruxism. Moreover, the prevalence of bruxism in young children can be difficult to diagnose, since children may not sleep in or near their parents' bedrooms. ${ }^{2}$ In addition, most signs and symptoms related to bruxism in young children are mild, and therefore difficult to detect ${ }^{26}$. Thus, bruxism can be underestimated in children.

Tooth wear (evaluated clinically) was associated with a greater prevalence rate of sleep bruxism among the children studied. Indeed, tooth wear is the most common clinical consequence of sleep bruxism, and is more severe in the primary dentition due to a lower degree of mineralization than in the permanent dentition. ${ }^{27}$ However, the sole observation of surface wear on hard dental tissues does not confirm the clinical diagnosis of sleep bruxism, since this situation may be associated with other conditions..$^{28}$ The literature also describes breathing disorders during sleep, headache, excessive jaw muscle activity, hypertrophy of the masticatory muscles, and problems involving the temporomandibular joint in individuals with bruxism, especially in more advanced cases. ${ }^{5}$ Other oral health-related issues, such as dentist visits and clinical conditions, did not reveal any influence on sleep bruxism in preschoolers. It could well be that the psychological issues of children ${ }^{2}$ are a greater influence on bruxism than oral health conditions.

Sleep quality was also associated with sleep bruxism in the children. The authors of a previous study found that sleeping fewer than eight hours a night, and sleeping with light and noise in the room were predisposing factors for the occurrence of sleep bruxism in children..$^{29}$ Moreover, children who snore and those who have nightmares are more likely to exhibit sleep bruxism. ${ }^{5}$ Thus, aspects of sleep quality may constitute a warning sign that can assist parents/caregivers and health professionals in identifying sleep bruxism early on, and thus limit its consequences. ${ }^{30}$

The parent's/caregiver's sense of coherence was not associated with sleep bruxism in the preschool children analyzed. However, psychosocial factors are probably among the aspects most closely related to the etiology of bruxism, especially in situations of stress and anxiety. ${ }^{31}$ The absence of this association in the present study may have been attributed to the young age of the children, and consequent lack of complications of this disorder. It may have also been due to the child's own psychological conditions ${ }^{2}$ bearing greater influence than the parent's/caregiver's sense of coherence.

The diagnosis of sleep bruxism based on the reports of parents/caregivers could be considered a limitation of the present study, since other diagnostic criteria, such as clinical examination, electromyography and polysomnography, would have been appropriate complements to such reports. However, parental reports are the criterion proposed by the AASM, ${ }^{10}$ and high costs limit the use of other diagnostic criteria, especially in an epidemiological investigation. ${ }^{8}$ Moreover, this study has the limitation inherent to its cross-sectional design, which does not allow the establishment of cause-and-effect relationships. Nevertheless, measures were taken to make the study representative of the population of fiveyear-old children, such as the use of probabilistic sampling and validated questionnaires. Studies with a longitudinal design are needed to gain a better understanding of the relationship between sleep bruxism and psychosocial aspects, such as sense of coherence, since early identification of signs and symptoms of this habit in preschool children could assist in the prevention of later problems.

\section{Conclusion}

In the present study, sleep bruxism among preschool children was associated with tooth wear and poor sleep quality of the child. In contrast, psychosocial aspects (parent's/caregiver's sense of coherence) were not associated with sleep bruxism.

\section{Acknowledgments}

This study was supported by the State University of Paraíba (UEPB), the Brazilian Coordination of Higher Education of the Ministry of Education (CAPES), the State of Minas Gerais Assistance to Research Foundation (FAPEMIG) and the National Council for Scientific and Technological Development (CNPQ), Brazil. 
Gomes MC, Neves ET, Perazzo MF, Souza EGC, Serra-Negra JM, Paiva SM et al.

\section{References}

1. Firmani M, Reyes M, Becerra N, Flores G, Weitzman M, Espinosa P. [Sleep bruxism in children and adolescentes]. Rev Chil Pediatr. 2015 Sep-Oct;86(5):373-9. Spanish. https://doi.org/10.1016/j.rchipe.2015.05.001

2. Fonseca CM, Santos MB, Consani RL, Santos JF, Marchini L. Incidence of sleep bruxism among children in Itanhandu, Brazil. Sleep Breath. 2011 May;15(2):215-20. https://doi.org/10.1007/s11325-010-0427-3

3. Insana SP, Gozal D, McNeil DW, Montgomery-Downs HE. Community based study of sleep bruxism during early childhood. Sleep Med. 2013 Feb;14(2):183-8. https://doi.org/10.1016/i.sleep.2012.09.027

4. Ferreira NM, Dos Santos JF, dos Santos MB, Marchini L. Sleep bruxism associated with obstructive sleep apnea syndrome in children. Cranio. 2015 Oct;33(4):251-5. https://doi.org/10.1179/2151090314Y.0000000025

5. Alencar NA, Fernandes AB, Souza MM, Luiz RR, FonsecaGonçalves A, Maia LC. Lifestyle and oral facial disorders associated with sleep bruxism in children. Cranio. 2016;22(1):1-7. https://doi.org/10.1080/08869634.2016.1196865

6. Saulue P, Carra MC, Laluque JF, d'Incau E. Understanding bruxism in children and adolescents. Int Orthod. 2015 Dec;13(4):489-506. https://doi.org/10.1016/i.ortho.2015.09.001

7. Machado E, Dal-Fabbro C, Cunali PA, Kaizer OB. Prevalence of sleep bruxism in children: a systematic review. Dental Press J Orthod. 2014 Nov-Dec;19(6):54-61. https://doi.org/10.1590/2176-9451.19.6.054-061.oar

8. Castroflorio T, Bargellini A, Rossini G, Cugliari G, Rainoldi A, Deregibus A. Risk factors related to sleep bruxism in children: A systematic literature review. Arch Oral Biol. 2015 Nov;60(11):1618-24. https://doi.org/10.1016/i.archoralbio.2015.08.014

9. Restrepo C, Peláez A, Alvarez E, Paucar C, Abad P. Digital imaging of patterns of dental wear to diagnose bruxism in children. Int J Paediatr Dent. 2006 Jul;16(4):278-85. https://doi.org/10.1111/j.1365-263X.2006.00756.x

10. American Academy of Sleep Medicine. International classification of sleep disorders. Westchester: American Academy of Sleep Medicine; 2005. Vol. 2.

11. Serra-Negra JM, Paiva SM, Seabra AP, Dorella C, Lemos BF, Pordeus IA. Prevalence of sleep bruxism in a group of Brazilian schoolchildren. Eur Arch Paediatr Dent. 2010 Aug;11(4):192-5. https://doi.org/10.1007/BF03262743

12. Bonanato K, Paiva SM, Pordeus IA, Ramos-Jorge ML, Barbabela D, Allison PJ. Relationship between mothers' sense of coherence and oral health status of preschool children. Caries Res. 2009;43(2):103-9. https://doi.org/10.1159/000209342

13. Antonio AG, Pierro VS, Maia LC. Bruxism in children: a warning sign for psychological problems. J Can Dent Assoc. 2006 Mar;72(2):155-60.
14. Browner WS, Newman TB, Hulley SB. Estimating sample size and power: applications and examples. In: Hulley SB, Cummings SR, Browner WS, Grady DG, Newman TB, editors. Designing clinical research. 3rd ed. Philadelphia: Lippincott and Williams \& Wilkins; 2007. p. 65-94.

15. Altman DG. Practical statistics for medical research. 2nd ed. London: Chapman and Hall; 2006.

16. Antonovsky A. Unraveling mystery of health: how people manage stress and stay well. San Francisco: Jossey-Bass; 1987.

17. Bonanato K, Branco DB, Mota JP, Ramos-Jorge ML, Paiva SM, Pordeus IA et al. Trans-cultural adaptation and psychometric properties of the 'Sense of Coherence Scale' in mothers of preschool children. Interam J Psyhicol. 2009;43(1):144-53.

18. Scarpelli AC, Paiva SM, Viegas CM, Carvalho AC, Ferreira FM, Pordeus IA. Oral health-related quality of life among Brazilian preschool children. Community Dent Oral Epidemiol. 2013 Aug;41(4):336-44. https://doi.org/10.1111/cdoe.12022

19. Gomes MC, Pinto-Sarmento TC, Costa EM, Martins CC, Granville-Garcia AF, Paiva SM. Impact of oral health conditions on the quality of life of preschool children and their families: a cross-sectional study. Health Qual Life Outcomes. 2014 Apr;12(1):55. https://doi.org/10.1186/1477-7525-12-55

20. Castelo PM, Barbosa TS, Gavião MB. Quality of life evaluation of children with sleep bruxism. BMC Oral Health. 2010 Jun;10(1):16. https://doi.org/10.1186/1472-6831-10-16

21. Lobbezoo F, Ahlberg J, Glaros AG, Kato T, Koyano K, Lavigne GJ et al. Bruxism defined and graded: an international consensus. J Oral Rehabil. 2013 Jan;40(1):2-4. https://doi.org/10.1111/joor.12011

22. Ismail Al, Sohn W, Tellez M, Amaya A, Sen A, Hasson $\mathrm{H}$ et al. The International Caries Detection and Assessment System (ICDAS): an integrated system for measuring dental caries. Community Dent Oral Epidemiol. 2007 Jun;35(3):170-8. https://doi.org/10.1111/j.1600-0528.2007.00347.x

23. Andreasen JO, Andreasen FM, Andersson L. Textbook and color atlas of traumatic injuries to the teeth. 4 th ed. Oxford: Blackwell; 2007.

24. Foster TD, Hamilton MC. Occlusion in the primary dentition. Study of children at 2 and one-half to 3 years of age. Br Dent J. 1969 Jan;126(2):76-9.

25. Grabowski R, Stahl F, Gaebel M, Kundt G. [Relationship between occlusal findings and orofacial myofunctional status in primary and mixed dentition. Part I: prevalence of malocclusions]. J Orofac Orthop. 2007 Jan;68(1):26-37. German. https://doi.org/10.1007/s00056-007-1606-0

26. Egermark I, Carlsson GE, Magnusson T. A 20 year longitudinal study of subjective symptoms of temporomandibular disorders from childhood to adulthood. Acta Odontol Scand. 2001 Feb;59(1):40-8. https://doi.org/10.1080/000163501300035788 
Evaluation of the association of bruxism, psychosocial and sociodemographic factors in preschoolers

27. Ferreira-Bacci AV, Cardoso CL, Díaz-Serrano KV. Behavioral problems and emotional stress in children with bruxism. Braz Dent J. 2012;23(3):246-51. https://doi.org/10.1590/S0103-64402012000300011

28. Mengatto CM, Coelho-de-Souza FH, Souza Junior OB. Sleep bruxism: challenges and restorative solutions. Clin Cosmet Investig Dent. 2016 Apr;8(1):71-7. https://doi.org/10.2147/CCIDE.S70715

29. Serra-Negra JM, Paiva SM, Fulgêncio LB, Chavez BA, Lage CF, Pordeus IA. Environmental factors, sleep duration, and sleep bruxism in Brazilian schoolchildren: a case-control study. Sleep Med. 2014 Feb;15(2):236-9. https://doi.org/10.1016/i.sleep.2013.08.797

30. Simões-Zenari M, Bitar ML. Factors associated to bruxism in children from $4-6$ years. Pro Fono. 2010 Oct-Dec;22(4):465-72. https://doi.org/10.1590/S0104-56872010000400018

31. Manfredini D, Lobbezoo F. Role of psychosocial factors in the etiology of bruxism. J Orofac Pain. 2009;23(2):153-66. 